\title{
Modern trends of electronic educational resources development at the university
}

\author{
Elena Shutyeva ${ }^{1}$, Tatiana Zenkova ${ }^{2 *}$, Valeriy Goncharov3, and Elena Kolomiychenko ${ }^{4}$ \\ ${ }^{1}$ Don State Technical University, 344003, Rostov-on-Don, Russia \\ ${ }^{2}$ Rostov State Transport University, 344038, Rostov-on-Don, Russia \\ ${ }^{3}$ K.G. Razumovsky Moscow State University of Technologies and Management, (the First Cossack \\ University), 109004, Moscow, Russia, \\ ${ }^{4}$ Southern Federal University, 344006, Rostov-on-Don, Russia
}

\begin{abstract}
The relevance of the development of electronic educational systems has long been one of the main topics for discussion not only at the level of universities, but also at secondary and basic education. Many higher educational institutions in Russia are actively using distance-learning technologies, which bring them to a qualitatively new level of interaction between the teacher and students. The purpose of the study is to analyze the effectiveness of the process of informatization of educational resources in the discipline "Physical culture and sports" at the university for further substantiation of the path of development of the digital environment in this discipline, regardless of the health level of students and their place of stay. The issues of the effectiveness of electronic educational resources in organizational and management activities in the field of physical culture and sports are analyzed. The directions of creation of a unified educational information system for universities with the possibility of maximum use of information resources in pedagogical activity, for specialists in physical culture and sports are considered. Thus, the main challenge for modern education in the field of physical culture and sports is the construction of an adaptive educational system that responds to the transformation of the environment, and the creation of conditions for the implementation of individual (personalized) educational trajectories using modern educational technologies.
\end{abstract}

\section{Introduction}

The relevance of the development of electronic educational systems has long been one of the main topics for discussion not only at the level of universities, but also at secondary and basic education. The transfer of all levels of education to remote work through electronic resources of educational institutions in the spring of 2020 revealed new tasks for teachers: the transition, forms of full-time (offline) education to online - without compromising the quality of education. The issue of expansion, development of teaching methods and methods in educational institutions arose sharply. In universities that build education on the basis of

\footnotetext{
* Corresponding author: zata-70@mail.ru
} 
FGOS VO $3++$ standards, basic general professional competencies should form the skills and abilities of working with modern software in the professional sphere.

The world community, at present, is actively developing information educational technologies that make it possible to study remotely in various disciplines on numerous informational platforms of open education, including those of the world's leading universities $[1,2,3]$. Many higher educational institutions in Russia are actively using the distance learning technologies, which bring them to a qualitatively new level of interaction between the teacher and students.

Distance learning supporters believe that it builds over -professional skills that help them to become flexible in any profession. And yet, they go well with full-time study teaching methods. This is confirmed by the increase in demand for distance education in American higher education institutions since 2011. Thus, studies conducted in 2013 in the United States indicate that $37 \%$ of respondents consider online classes to be of the same quality as classical education [4].

In Russia, the possibility of using educational standards with the introduction of distance educational technologies is legitimate and is reflected in the Federal Law on Education, where "distance educational technologies" are interpreted as non-contact interaction between a teacher and a student through electronic information, television and communication resources. The basic settings of online learning are based on the content of the project "Modern Digital Educational Environment in the Russian Federation". The implementation of this project provides that by the end of 2021 with the use of online technologies, more than six million students will study in our country. The key directions of the development of Russian education should be aimed at "expanding the field of digitalization as the most important trend not only in the educational process, but also in other areas of the functioning of universities." The situation with the transition to distance learning at all levels of education, which developed during the introduction of restrictive measures, refers to the fundamental points not only the pedagogical skills of teachers, but also the ability to apply them in the course of classes, the maximum number of technical equipment (laptops, desktop computers, headsets, graphics tablets) $[5,6]$.

Developing an individual approach to students in the course of distance education is a strong positive argument in favor of using online technologies. However, there are still a lot of problems with the most competent application of information educational technologies of teaching at the university. The problem of distance learning in higher education is disclosed in the work of A.V. Nushtaeva, where the author points to the increasing role of students' independent work. At the same time, a scheme for constructing a training model is proposed, but the need to change the form of presentation and control of the material is indicated. And independent work and the volume of lecture material should not increase the cognitive load on students [7]. Such work, in turn, implies an important feature of distance learning: the need to build an individual version of the assignment for each student or separate assignments for each group of students in the case of teamwork. At the St. Petersburg State Pediatric Medical University, when studying a chemistry course, the main emphasis is on the fact that distance learning is not only the work of students on themselves, but also becomes the basis for the development of a teacher. Since the teacher himself draws up a work plan for each student individually, based on his mistakes in test papers, he is also in constant search of new data and methods of presenting material on the issue under study. The maximum effect of online learning involves the introduction of virtual reality technologies. Thus, the methods, assignments, teaching aids used in the full-time training format when transferring to the distance format require colossal processing. Therefore, the main vector of modern distance education is the construction of a unified adaptive electronic system corresponding to the transformations of modern trends, and the creation of conditions for the implementation of individual educational trajectories. 
At the forum "The Global Future of Education" held in Moscow in 2017, experts discussed the foresight-forecast of the Agency for Strategic Initiatives "Education 2030", which determined the following directions for the development of Russian modern education:

- shift of the education vector to the Internet;

- individualization of the learning process, i.e. shifting its content to the characteristics of the student.

Hence, the number of people receiving education should increase, but at the same timeindividual educational strategies based on new technologies should be observed. These factors will help to reduce the education costs of young people. That is, the key role will be assigned to the personal educational environment, which is a mechanism for adaptation to modern changes in educational technologies, and becomes a source of cognitive informational educational activity of a student. Classical higher education based on the competencies of developing systemic and critical thinking, self-organization and selfeducation will adapt to new educational tasks. In the future, some of the higher educational institutions may be transformed into a kind of consulting, practice-oriented centers. And by 2030, according to the results of a number of studies, $186 \mathrm{new}$, not yet existing professions will appear [8]. In turn, the digital educational environment in the field of physical culture and sports has a number of its specific features [9]. Since the problem of the formation of physical culture of the students ' personality is reflected in a large number of scientific works, in the current situation, the question is: how will young people use the acquired skills in the new realities? Will they be able to competently and effectively use modern electronic resources in the field of physical culture and maintaining their health? $[10,11,12]$.

Research of coaching and pedagogical teams is aimed at identifying the main difficulties in working with electronic educational resources in the implementation of the remote teaching and training process [13].

Problematic aspects of physical culture disciplines realization for teachers were: the lack of the possibility of using sports facilities and part of the sports equipment, the impossibility of correcting mistakes when performing a motor action. We can also add to them a weak development of means, methods, stages of teaching planning of the annual cycle and training load with in-depth work with students in this area [14]. At the same time, the analysis of the effectiveness of physical culture and sports classes should include not only the social, household and technical capabilities of each student, but also correspond to the level of health and physical qualification of each student [15]. In his work, Sadovnikov E. S. [16], points out that the adaptation of physical culture and recreation activities of students should be carried out by including a situational and adaptive component in its structure. In the current situation of life restriction conditions, the main task of each person is to take care of their health. This sector of physical education needs to be moved to the field of self-education and self-organization of physical culture and recreation activities. The basis of self-education should be lectures and theoretical and methodological classes, the number of which should be constantly increased. At the same time, all their efforts in this direction should be directed to the study of the mechanisms of stress and the ability to manage them with health-saving tools $[17,18,19]$.

The purpose of the study is to analyze the effectiveness of the process of informatization of educational resources in the discipline "Physical culture and sports" at the university for further substantiation of the path of development of the digital environment in this discipline, regardless of the health level of students and their place of stay. Avoiding the classical structure of training sessions in the discipline "Physical culture and sports" at the university due to the management of synergistically combined mechanisms of Internet resources.

\section{Materials and Methods}


The research base consists of electronic educational platforms and publications, online courses, mobile applications, and Internet sites. We studied 1,150 anonymous reviews (360 full - time students, 790 part-time students) - regarding the content of remote physical education and sports classes-content presented on the Internet. The received reviews were sorted by blocks: indicators of satisfaction with the effectiveness of physical culture classes at the university, factors that cause a negative attitude to the discipline "Physical Culture and Sports", the most popular training areas for physical culture classes. Reviews were analyzed for each block. For each block of questions, the average number of responses was obtained, as well as the percentage of the total number of students.

To assess the effectiveness of the process of informatization of electronic resources, a questionnaire was used in the form of a questionnaire survey, which included a number of questions obtained as a result of a literature review. The survey was conducted anonymously. The respondents were the teaching staff (64 people, including 13 teachers under 40 years old, 20 people-41-60 years old, 31-over 60 years old).

The analysis of the literature on the problems of remote work with various electronic resources in the field of physical culture and sports is carried out and systematized.

A remote method of teaching online learning has been developed that considers not only the social and technical capabilities of each student, but also the individual characteristics of the health and physical fitness of young people.

\section{Results}

Based on the results of the reviews studied, components were identified that show the topology of interactive characteristics with the fundamental motives of the students (Table 1). The concepts of "boredom", "trash", "waste of time" indicate a conflict between the expected and real effectiveness of training, lead to a loss of personal meaning of training and doubts about the attainability of the desired conditions. Physical culture is perceived by young people as introverted in their capabilities and extroverted in their uselessness. The level of maintenance of motivation to trainings is supported only by obtaining a "credit" (591 $\pm 0.6)$.

Table 1. Quantitative and qualitative indicators of students ' attitude to classes in "Physical culture and sports" in remote mode.

\begin{tabular}{|l|c|c|c|c|c|c|}
\hline \multicolumn{1}{|c|}{ Reviews / result } & \multicolumn{2}{c|}{ positive } & \multicolumn{2}{c|}{ negative } & \multicolumn{2}{c|}{ neutral } \\
\hline Effectiveness of classes & $581 \pm 0.4$ & $51 \%$ & $252 \pm 0.1$ & $22 \%$ & $317 \pm 0.2$ & $27 \%$ \\
\hline $\begin{array}{l}\text { Factors showing the } \\
\text { attitude to the discipline " }\end{array}$ & & & & & & \\
$\begin{array}{l}\text { Physical culture and } \\
\text { sports»: }\end{array}$ & & & & & & \\
$\quad$ - monotony of classes & $475 \pm 0.6$ & $41 \%$ & $529 \pm 0.4$ & $46 \%$ & $146 \pm 0.1$ & $13 \%$ \\
- authoritarianism of & $536 \pm 0.4$ & $47 \%$ & $449 \pm 0.2$ & $39 \%$ & $165 \pm 0.2$ & $14 \%$ \\
teachers & & & & & & \\
- deprecated methods & $742 \pm 0.2$ & $65 \%$ & $245 \pm 0.4$ & $21 \%$ & $163 \pm 0.4$ & $14 \%$ \\
- obsolete phraseological & $296 \pm 0.1$ & $26 \%$ & $681 \pm 0.1$ & $59 \%$ & $173 \pm 0.2$ & $15 \%$ \\
units & & & & & & \\
\hline The most popular & & & & & & \\
training areas for & & & & & & \\
physical education: & & & & & & \\
- dance & $207 \pm 0.1$ & $18 \%$ & $515 \pm 0.8$ & $45 \%$ & $428 \pm 0.2$ & $37 \%$ \\
-strength training & $609 \pm 0.4$ & $53 \%$ & $448 \pm 0.4$ & $39 \%$ & $93 \pm 0.4$ & $8 \%$ \\
- functional training & $397 \pm 0.2$ & $35 \%$ & $568 \pm 0.4$ & $49 \%$ & $185 \pm 0.2$ & $16 \%$ \\
- sports games & $783 \pm 0.1$ & $68 \%$ & $166 \pm 0.2$ & $11 \%$ & $201 \pm 0.1$ & $31 \%$ \\
- swimming
\end{tabular}




\begin{tabular}{|l|l|l|l|l|l|l|}
\hline - combative sport & $592 \pm 0.3$ & $51 \%$ & $420 \pm 0.2$ & $37 \%$ & $138 \pm 0.3$ & $12 \%$ \\
& $351 \pm 0.3$ & $30 \%$ & $607 \pm 0.4$ & $53 \%$ & $192 \pm 0.3$ & $17 \%$ \\
\hline
\end{tabular}

This is due to unfulfilled expectations of "flexibility" in the use of repetitive tools in practice. Students have a negative attitude to phraseological units and terms used during teaching pairs and the authoritarianism of teachers $(563 \pm 0.4)$.

At the same time, Internet content creates a conflict in young people between the cult branding created on the Network and the stress that occurs during a real adaptation to the load $(612 \pm 0.1)$. A large selection of training programs in the network creates a need to improve the quality of training sessions $(391 \pm 0.3)$. Students expect that by coming to classes they will be able to gain skills in various fitness programs. At the same time, many students do not see the difference between the disciplines "Physical Culture and Sports" and "Elective courses in physical culture and sports". And therefore, they have a feeling of disappointed expectations.

In addition, many sports areas require the student to be physically involved in the process, you cannot learn how to perform a serve in volleyball or high jump, just by watching the competition or reading the manual. And if you add to the lack of motor skills of perception of motor actions the lack of the ability to use sports facilities and sports equipment, then the question arises about the development of students ' competencies prescribed in state standards.

There is a trend of a widespread decrease in the academic hours allocated for physical education classes in universities, which also plays a negative role. The hours allocated for independent work of students do not regulate the passage of the material in any way. Often, students do not know what to do and how to do it.

At the same time, a number of important contradictions also arise in the work of the teaching staff. On the one hand, the average age of teachers is over 55 years old. Some of them do not have a home computer or internet access. Consequently, there are no skills to work with electronic resources. Thus, only a third of teachers have user skills $(23 \pm 0.4)$. Half of them can use only standard software. And only $20 \%$ of teachers can compose a video presentation or use modern Internet resources. The data obtained are reflected in Table 2.

Table 2. The work of the teaching staff with electronic resources (number of people).

\begin{tabular}{|l|c|c|c|}
\hline Electronic resources & TS up to 40 years & TS 41-60 years & TS 60 over 60 years \\
\hline $\begin{array}{l}\text { Working in your } \\
\text { personal account }\end{array}$ & 13 & 20 & 26 \\
\hline $\begin{array}{l}\text { Knowledge of } \\
\text { standard programs }\end{array}$ & 11 & 17 & 20 \\
\hline $\begin{array}{l}\text { Compilation of video } \\
\text { and media files }\end{array}$ & 5 & 5 & 7 \\
\hline $\begin{array}{l}\text { Use of modern } \\
\text { Internet resources }\end{array}$ & 10 & 8 & 12 \\
\hline
\end{tabular}

Information support of physical culture is based on theoretical knowledge and the logic of objective laws. In the field of informatization, a regular exchange of experience is required, which is entrusted to methodological support. A modern development of methods and research in the field of informatization in the discipline "physical culture and sports" is required. The positive dynamics of the informatization process in sports should be provided by Internet access and technical support of departments and faculties of physical culture. They will serve as the basis for the implementation of activities and telecommunications of the taught discipline. The percentage of the work of the teaching staff with electronic resources is shown in Figure 1. 
The work of the teaching staff with electronic resources (\%).

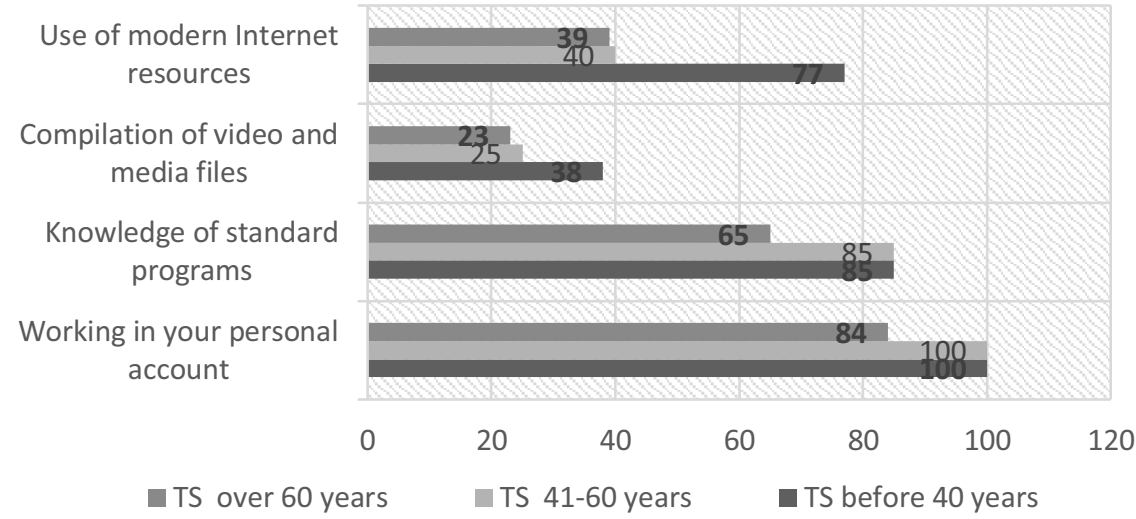

Fig. 1. The level of proficiency of teaching staff in computer technologies.

The high-quality functioning of telecommunications in the field of physical culture and sports is based on a whole complex of consistently coordinated structured stages of activity.

The first step of this activity should be the creation of innovative computer programs not only for the capital, but also for the regions in the direction of "Physical Culture and Sports". Without updating the educational and methodological base, all efforts will not work effectively.

The next stage is the formation of information services in the field of physical culture and sports. The number of training sites and programs should meet any needs. And the proposed content, in its diversity, is based on existing innovative developments in this area.

To work with the created Internet resources, training, training and retraining of qualified specialists is required. So, the equipment without proper use becomes only a pile of metal. In addition, the availability of new-generation technical equipment is also mandatory.

The teaching staff should, in turn, divide the information received into qualitative and false. Since there are always unscrupulous content providers.

An important stage, then, is the financing of sports and physical culture and recreation work. To do this, there must be both budgetary and commercial means of financing.

The next step is the processing and protection of the received information. Thus, it is necessary to achieve transparency of the activities of all structures of sports and recreation activities.

Communication and coordination activities between sports organizations, departments, federations and management structures become the foundation for building digitalization of all systems of physical culture and sports activities. These organizations in the context of digitalization can and should have a common database, and a structure that regulates and coordinates their activities.

Informationology studies the origin of data, information flows, and other phenomena in the surrounding world. It becomes an assistant in the implementation of the tasks of the educational and training process for both teachers and students.

The creation of favorable conditions for the development of informatization of sports and recreation activities as a specific environment is conditioned by a number of interrelated provisions:

1. registration and research of sports competitions, sports events, implementation of educational disciplines on the subject "Physical culture and sports", etc.;

2. classification and standardization of methods and exercises that are used to test and evaluate physical fitness; 
3. development of modern models and technologies of training in the field of sports and recreation activities and their implementation in practical work;

4. systematization of information codes and creation of a working system for accessing them;

5. legal support and information protection;

6. creation of an interdepartmental electronic Internet system of communication and information technologies for the provision of services in the field of sports and recreation work with the population through the use of satellite, cellular and mobile communications;

7. study of computer modeling of individual components of the educational process in the field of physical culture and sports;

8. formation of a common information database of physical culture and sports facilities (legislative acts, the state and number of training bases and sports facilities, trends in the development of international student sports, the availability of specialists in various fields and their level of qualification, changes and current standards for checking and evaluating the physical fitness of students.

The successful functioning of the branches of physical culture and sports directly depends on informatization, which includes scientific and technical support, methodological and scientific support, monitoring, material regulation and organizational measures. Monitoring involves analyzing multiple sources of information, followed by synthesizing the received data. The monitoring system is effective at any level of management: sports clubs, sports federations, ministries, departments of physical culture at universities, etc. Informatization makes it possible to find problems in the field of physical culture and sports, helps to create an expert opinion and a variety of ways to solve the identified difficulties. So, with the help of analysis and peer evaluation, it gives the opportunity for a qualitative assessment of sports results, national teams, individual achievements, etc., indicating the positive and negative aspects of training.

\section{Discussion}

The key position in online education undoubtedly belongs to the Internet, which has taken the position of the navigator of the diversification of the discipline "Physical Culture and Sports". Internet resources form an image about the values of physical culture and the life attitudes of young people, their lifestyle, and should be used in the diagnosis of the entropy of physical culture in general.

The main factor hindering the development of distance learning in physical culture and sports in Russia was the lack of high-quality Internet content. This state of affairs has already been formed quite a long time ago. Modern classical education, has a lack of choice of wellwritten textbooks in all educational areas. But, this is an additional consequence, and not the cause of the problems that have arisen. The criticality of the situation is that electronic textbooks, electronic lectures, and courses are just a translation of paper into electronic form. Due to the fact that in practice, there is no transformation of the generally accepted classbased form of education into an online format and the process of digitalization of the educational process is slowed down. And modern youth, who spend a lot of time in the Internet space, are not ready for independent study of academic disciplines. Even those offered in the electronic form.

The increasing demand for online education in the West $[20,21]$ can be justified from the point of view of the use of distance learning tutors. This practice was formed quite a long time ago. The tutor is engaged in the activation of the academic course, helps to follow the individual learning path. Creates for the student a complex process relationship of educational materials with the practice of their application $[22,23]$. 
Distance learning can be replaced by correspondence or second higher education. The first higher education should be only full-time and classroom-based, or mixed with a predominant share of full-time classes. Studies have revealed the unwillingness of the teaching staff to fully switch to the online mode. Among the main problems remain: the lack of high-quality Internet content and technical equipment in the field of electronic educational resources.

The next most important factor is the need for teachers who possess not only professional competencies, but also know how to work with the Internet resources of modern educational programs. Methodological training of the coaching and teaching staff for working in the distance learning system is not included in the training courses of the disciplines of universities and institutes of advanced training. At the same time, the need for such personnel increases even more. Therefore, to improve the quality of the teacher's activity, online disciplines should be taught as a tutor, using existing developments [18] and applying a systematic approach to teaching. In Russia, such courses are at the stage of formation, and the existing ones do not meet the real needs of the rapidly developing digitalization of physical education.

The formed new educational system becomes an inhibitor of the growth of academic mobility of students. Its content helps to bring physical education to the next level of the formation of universal values that are accepted outside of a particular country. Which, accordingly, becomes the basis for the emergence of a global network of consulting, practiceoriented educational centers and corporations

High-quality implementation of informatization in the field of physical culture and sports includes the creation of a single information base of all sports and recreation structures and methods of transmitting this information among themselves. The effectiveness of the development and work of sports and recreation organizations is based on their informatization. Which, in turn, should include scientific, technical and methodological support, monitoring and diagnostics, material regulation and organizational measures. Thus, it is necessary to create a unified information educational system for universities with the possibility of maximum use in pedagogical activities of information resources for specialists in physical culture and sports.

The results of the study show that the Internet belongs to modern culture, where a new social model of physical culture is being formed. The analysis of the studied scientific literature forms new laws, norms and terminology in the field of physical culture and sports. The data obtained can be used to make physical education and sports accessible to everyone, and to increase the relationship between practical and theoretical classes.

\section{Conclusion}

The established methods of work, tasks, and teaching aids used in classical training during the transition to a remote format require a qualitatively new approach and complete processing.

The requirements for learning outcomes, as universal competencies, should include the competencies of systematic and critical thinking, the competencies of project development and implementation, teamwork and leadership, self-organization and self-education.

To achieve the best results in learning, as a mutual process of acquiring and developing knowledge not only by students, but also by teachers, a mixed approach with the use of distance learning and real traditional full-time classes is important.

Information about the totality of factors in the field of sports and physical culture is factographic information. The varieties of such information in organizational and managerial matters are ranked into reporting, statistical, sports, etc. In turn, the reporting information is transmitted in documents that have a certain form. Statistical-includes the initial information 
obtained as a result of initial observations. Sports-represents technical results, such as competition results, etc. Information resources and the ability to structure them help to create arrays of necessary documentation and methods for transmitting information. At the moment, the main problem is the lack of information processing tools in the physical culture and sports environment, which are essential for their formation and application.

The key direction of the development of modern online education is the construction of an adaptive educational system that adapts to the changing conditions of the outside world, and the introduction of individual (personalized) educational trajectories into the learning process, considering not only the social and technical capabilities of each student, but also the corresponding level of health and physical fitness of each student.

Reliable functioning of informatization in the field of physical culture and sports is ensured by the formation of a single information base of all levels of sports and recreation orientation and methods of transmitting this data among themselves. The progression of the growth of sports and sports departments is closely interrelated with the development of informatization, consisting of scientific, technical and methodological support, monitoring and diagnostics, material regulation and organizational measures.

It is necessary to create a unified information educational database for educational and sports organizations in the field of sports and recreation activities with the possibility of maximum use in pedagogical activities of any innovative information resources for specialists in physical culture and sports.

The results obtained in the course of the study can be used in the development of distance learning programs for students not only in the discipline "Physical Culture and Sports".

\section{References}

1. Stella A. Gnanam, Higher Education 47, 143-160 (2004)

2. J. June, International Journal on E-Learning, Norfolk, VA: AACE 4(2), 229-240 (2005)

3. C. Dondi, M. Moretti, Elearning quality in European universities: different approaches for different purposes, Report Agreement number. $1425 / 001 \quad-001$. http://unique.europace.org/pdf/WP1-report-v5 (2007).

4. Z.M. Sarkisyan, Modern science-intensive technologies 6(2), 364-368 http://toptechnologies.ru/ru/article/view?id=38117 (2020).

5. V.P. Ignatiev, E.A. Arkhangelskaya, Modern science-intensive technologies 6(1), 138142 (2020) http://top-technologies.ru/ru/article/view?id=38083

6. O.V. Prikhodko, Modern science-intensive technologies 4, 147-151 (2019) http://toptechnologies.ru/ru/article/view?id=37507

7. A.V. Nushtaeva, Modern science-intensive technologies 6(2), 353-357 (2020) http://toptechnologies.ru/ru/article/view?id=38115.

8. N.S. Ladyzhets, E.V. Neborskiy, Internet-journal "Science of Science" 7(2), 143 (2015)

9. N.Yu. Surova, T.N. Shutova, L.B. Andryushchenko, A.G. Rostevanov, Theory and practice of physical culture and sports 1, 47 (2021)

10. P.C. Borstorff, S.K. Lowe, Academy of Educational Leadership Journal 11(2), 13-29 (2007)

11. M. Stănescu, N. Mușat, M. Stoicescu, Features of the learning process in sports continuing education programs that use the blendedlearning system, Proceedings of the 10th ELSE Conference, Bucharest, Romania. IV, 109-119 (2014) 
12. U.D. Ehlers, Quality in e-Learning from a Learner's Perspective, Proceedings of the 3rd EDEN Research Workshop (Oldenburg, Germany) http://www.eurodl.org/materials/contrib/2004/Online_Master_COPs (2004).

13. I.L. Levina, A.A. Artemiev, Physical culture: upbringing, education, training 6, 45 (2020)

14. A.V. Rodin, D.V. Guba, V.P. Guba, L.V. Bulykina, Physical culture: upbringing, education, training 6, 74 (2020)

15. L.Yu. Averina, N.A. Bannikova, G.S. Kozhanov, Physical culture: upbringing, education, training 6, 3 (2020)

16. E.S. Sadovnikov, Theory and practice of physical culture 11, 85 (2020)

17. V.I. Grigoriev, V.A. Chistyakov, A.A. Obvintsev, Scientific Notes of the University P.F. Lesgaft 9(175), 58-64 (2019)

18. V.I. Grigoriev, Influence of the Internet on the development of elective physical culture in the university, Physical development of students in the modern world: materials of the international scientific-practical conference, St. Petersburg, April 11, 2019 - SPb. 3-17 (2019)

19. G.P. Vinogradov, V.I. Grigoriev, I.G. Vinogradov, Scientific Notes of the P.F. Lesgaft. 4(146), 46-50 (2017)

20. U.D. Ehlers, L. Goetz, B. Hildebrandt, J.M. Pawlowski, Quality in e-learning. Use and dissemination of quality approaches in Europeane-learning. A study by the European Quality Observatory (Office for Official Publications of the European Communities, Luxembourg, 2005).

21. P.S. Sajia, International Journal of Education and Development using Information and Communication Technology (IJEDICT) 4(1), 109-119 (2008)

22. P.G. Bordovskiy, Physical culture: upbringing, education, training 1, 61-63 (2018)

23. T.A. Zenkova, Information support of physical culture and sports in the framework of organizational and managerial issues, Physical culture and sport: integration of science and practice: materials of the XVII International scientific and practical conference (December 25, 2020), Stavropol, Publishing house of NCFU, 154-157 (2020) 